\title{
ENTREVISTA: PROFESSORA SOCORRO FERRAZ
}

\section{INTERVIEW: PROFESSOR SOCORRO FERRAZ}

\author{
Entrevistadora: Anne-Marie Pessis ${ }^{1}$ \\ annepessis@gmail.com
}

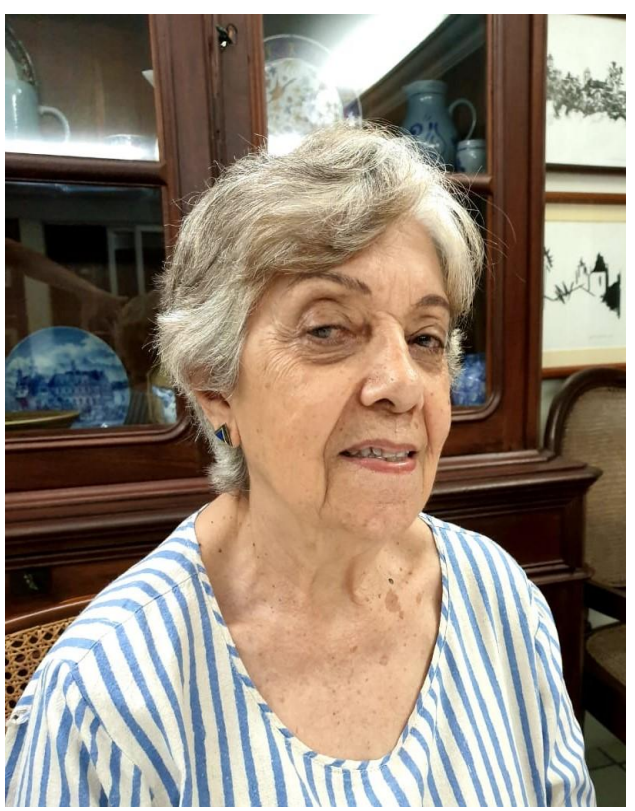

A Professora Maria do Socorro Ferraz Barbosa, bacharel e licenciada em história pela Universidade Federal de Pernambuco em 1961, concluiu o doutorado em história pela Universidade de São Paulo em 1992. Realizou estudos doutorais na Universidade de Bielefeld, Alemanha, entre 1975 e 1980. Foi professora do Departamento de História e do Programa de Pós-Graduação em História entre 1980 e 2012 e pesquisadora bolsista do $\mathrm{CNPq}$ e da CAPES. Integrou a Comissão Estadual Memória e Verdade Dom Helder Câmara, entre 2012 e 2017 e dedicou-se a pesquisas de temas, principalmente, relacionados às elites políticas, liberalismo, a ocupação do sertão, propriedade e escravidão e teorias e metodologias da história.

\footnotetext{
${ }^{1}$ Fumdham, Programa de Pós-graduação em Arqueologia, UFPE.
} 


\section{Clio: Qual o papel da história na disciplina arqueológica?}

Professora Socorro Ferraz: Esta é uma pergunta fundamental. A história colhe os achados da Arqueologia, que tem seus próprios métodos científicos de análise, e, junta a estes, informações de outras fontes. Assim pode realizar sua narrativa

Na Antiguidade a história disputava espaço com as ciências da natureza e sua posição era menos respeitada porque para os antigos a natureza era eterna e os homens mortais com maior possibilidade de se aproximar da verdade. A intensidade desta relação foi bastante dependente dos conceitos de História, que mudaram ao longo da cronologia histórica. Portanto, esta relação não foi sempre a mesma. $\mathrm{Na}$ Antiguidade a história disputava espaço com as ciências da natureza e sua posição era menos respeitada porque para os antigos a natureza era eterna e os homens mortais. Este conceito aprofundou uma ruptura entre as ciências chamadas naturais e as ciências humanas. 
Nesse período a história esteve mais ligada à retórica do que à poética. Se entendermos a história como registro do passado da humanidade, perceberemos que já se fazia história antes mesmo de uma sistematização de métodos e técnicas dessa disciplina, que não é regida por leis, portanto não pode ser considerada ciência, dentro do conceito das ciências exatas. Nesse sentido a Arqueologia se

A ação e a contemplação

\section{foram concebidas} em oposição, não em repulsão aproxima muito mais das ciências da natureza; para acelerar suas descobertas e se certificar do que elas representam, a Arqueologia necessita da tecnologia. $\mathrm{Na}$ antiguidade clássica a História se aproximou da filosofia e desta forma, adquiriu um pouco mais de prestígio. Esta aproximação e lhe possibilitou uma classificação entre as disciplina da contemplação em oposição ao conceito de ciências da ação, onde se alojou a Arqueologia. Entretanto, prefiro pensar que a arqueologia tem uma natureza mais complexa; ao se realizar como disciplina da ação pode contribuir para as disciplinas da contemplação. A definição de arqui: o ponto de partida, já dá o norte da importância dessa disciplina. 
Clio: Então a arqueologia como disciplina seria uma ruptura nessa percepção dicotômica do passado?

Professora Socorro Ferraz: Não, a arqueologia é uma disciplina que emprega processos de escavação e coleta de materiais, que foram utilizados por sociedades muito antigas ou mesmo contemporâneas. A ação e a contemplação foram concebidas em oposição, não em repulsão. Uma pode auxiliar a outra. Com a modernidade (séculos XVIII e XIX) o conceito de história mudou.

\section{A Arqueologia se interessou muito antes que a história pelo cotidiano das sociedades}

Ao invés de valorizar fatos extraordinários, disciplina passou a vê-los como a ponta do iceberg e se apoiou em outros conceitos como o de infraestrutura e superestrutura. A partir daí, com a metodologia de encadear os fatos levou ao conceito de processo. Para tanto, a prova na história passou a ser exigida Como requisito número um para se alcançar a verdade histórica. Os achados arqueológicos muitas vezes representaram a prova que faltava para o encadeamento dos fatos. 
Clio: E como se percebe essa transformação do passado a partir da arqueologia?

Muitos dos achados encontrados pelos arqueólogos ajudavam a História a confirmar a autenticidade e a verdade sobre os acontecimentos extraordinários. Nessa época, a História aproximou-se mais das ciências físicas porque algumas

\section{Não é uma} fragmentação. $\dot{E}$ uma parte, é o estudo, digamos assim, de uma parte da história

leis econômicas passaram a subsidiar alguns argumentos históricos auxiliando na interpretação dos fatos. Na pósmodernidade, quando o cotidiano das sociedades passa a ser valorizado, os rastros deixados pelos humanos e encontrados pelos arqueólogos foram de grande valia para se escrever a história desses povos. A Arqueologia se interessou muito antes que a história pelo cotidiano das sociedades. A alimentação, o vestuário, o ritual mortuário, fragmentos de cerâmica e outros vestígios que induzem a construir o cotidiano de um grupo ou de uma sociedade. 
Clio: A Senhora considera então que a arqueologia é uma fragmentação da história?

Professora Socorro Ferraz: Não. Não é uma fragmentação. É uma parte, é o estudo, digamos assim, de uma parte da história e que os historiadores não podem alcançar sozinhos. Mas isso é próprio da história. Quando se identificam coisas, vestígios de sociedades que não tinham escrita e não deixaram nada escrito apenas a pré-história, a partir das ciências naturais e com o auxílio das exatas, pode entender seu cotidiano, sua miudeza.

Clio: Então qual a postura de teóricos famosos, por exemplo, como Marx e Nietsche em relação a esses conceitos antigos de ação e contemplação da história?

\section{os que a}

contemplavam

estavam no topo da

pirâmide, os reis, os

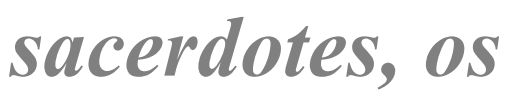

escribas
Professora Socorro Ferraz: Esses

conceitos lhes perturbaram;

principalmente ao Marx. Na esfera da pirâmide social quando se desenha uma sociedade de classes, os que a contemplavam estavam no topo da pirâmide, os reis, os sacerdotes, os escribas e, aquele que construíam os seus bens materiais estavam no último patamar, e, eram 
na verdade, os que deixavam para as outras gerações os feitos, os rastros. E aí a História aparece juntando os fios dos acontecimentos. O que propõe Marx? Inverter o lugar dos homens nessa pirâmide. Os que agem materialmente falando vão para o ápice da pirâmide e os que contemplam se localizam em baixo. Nessa

\section{A narrativa poderá ser feita} por um

\section{arqueólogo ou um historiador}

visão quem tem papel importante nas mudanças das sociedade não são os contemplativos, mas o indivíduo comum, é ele que deixa os rastros dos feitos daquela sociedade.

Mesmo quando o historiador encontra documentos escritos sobre determinada época, os vestígios, encontrados podem lhe dar a autenticidade e a prova que ele precisa. Muitas vezes os vestígios materiais revelam ao historiador indícios de verdades que os documentos não foram capazes de registrar ou mesmo ocultaram.

\section{Clio: Em sociedades que não tem escrita como se dá então essa narrativa do passado?}

Professora Socorro Ferraz: Nas sociedades ágrafas, essa narrativa é construída a partir dos achados arqueológicos como pinturas, material lítico, cerâmicas e das práticas antropológicas como religiosidade, padrões de comportamento, e outros. 
Outras ciências vão auxiliar na pesquisa, exemplo a química, a física, a geologia, a paleontologia, pois há que se datar, fazer medições, análises químicas e outras. A narrativa poderá ser feita por um arqueólogo ou um historiador. Com este leque de informações e de indícios o pesquisador poderá fazer a descrição da trajetória de um grupo humano. Em geral o arqueólogo apresenta o resultado das escavações diante de uma pergunta e um problema, anterior à escavação. As respostas a essa indagação pode trazer indicadores que solucionem o problema ou não.

\section{Clio: Como a história pode e deve contribuir em trabalhos de arqueologia.}

\section{A Arqueologia não é} apenas a técnica de escavar e encontrar artefatos, objetos catalogáveis. $\boldsymbol{O}$ arqueólogo não é aquele especialista em limpar objetos
Professora Socorro Ferraz: Acho fundamental essa simbiose entre as duas disciplinas. Quando um pesquisador inicia um trabalho, uma pesquisa, uma escavação e encontra vestígios de atividades humanas ele precisa datar esses achados; de posse dessa informação ele deve se informar sobre o período histórico, ao qual esses vestígios pertencem. 
A Arqueologia não é apenas a técnica de escavar e encontrar artefatos, objetos catalogáveis. O arqueólogo não é aquele especialista em limpar objetos e descrevê-los. Isto é a primeira parte. Depois vem a complementariedade das outras áreas do conhecimento, que podem e devem contribuir para um resultado mais completo.

Assim também como um historiador, quando inicia estudos sobre um período, tem que conhecer muito bem o que se passava naquela sociedade, não apenas na política, mas em várias áreas do conhecimento, como direito, filosofia, religião. Por exemplo, se um historiador trabalha sobre as grandes navegações tem que saber da importância da astronomia, da matemática, naquele período e da contribuição da tradução do livro de Ptolomeu - Geografia, para o latim, no início do século $\mathrm{XV}$, que alterou o modo como o mundo era imaginado e representado. Cabe ao historiador compreender qual contexto permitiu que ocorressem os grandes descobrimentos.

\section{Clio: Para um jovem arqueólogo quais livros a Senhora recomendaria.}

Professora Socorro Ferraz: Recomendaria um autor, Yuval Noah Harari, que escreveu Sapiens - Uma Breve História da Humanidade e Homo Deus - Uma Breve História do Amanhã. Recomendaria também o livro Neandertal dos autores Silvana Condemi e François Savatier, que lhes fazem uma crítica sobre a posição de Harari ante o homem de Neandertal. Outro livro que considero importante é o 
Homem Antes da Escrita. Este livro é assinado por vários autores, coordenado por André Varagnac, e faz parte da coleção Rumos do Mundo. Lembro ainda a autora e pesquisadora Gabriela Martin com o seu livro Pré-História do Nordeste, leitura obrigatória para os que fazem arqueologia, nessa região. 